\title{
Agent Commission and Coordinated Pricing For Online Group-Buying Channel
}

\author{
Hailin $\mathrm{Su}$ \\ Jiaxing University \\ School of Business \\ Jiaxing, China \\ shuimeimumu1982@126.com
}

\author{
Dake Qian \\ Jiaxing University \\ School of Business \\ Jiaxing, China \\ checkout@163.com
}

\begin{abstract}
Group-buying on the web is a new network selling mechanism which is developed and popular in decade. This paper constructs a online group-buying channel with sellers and agents to analyze price coordination. In Online groupbuying channel, agents affect the sellers' group-buying price by commissions, and agents can get more revenue if they formulate the commission in accordance with the price sequence formulated by the sellers. The paper analyzes the problem of "double marginalization effect" when the agent and seller non-cooperative in online group-buying channel. The paper also analyzes the cooperative mechanism when cooperation cost is less than the channels total revenue increment.
\end{abstract}

Keywords- online group-buying; agent; commission; coordinated pricing

\section{INTRODUCTION}

Online group-buying is a new network selling mechanism which is developed and popular in decade. The distinguishing feature of group-buying is that products' prices are determined by the accumulative purchase quantity. This mechanism requires the seller to set buy price sequence (descending order) and the accumulative purchase quantity of each price conditions (increasing order) in a period of time. When purchases reach or exceed one or more price qualifications, the transaction deals according to the lowest price in the qualifications. [1] Online group-buying has become an important online channel in the rapid development of e-commerce applications which mainstream channel mode is composed by sellers and agents. Online group-buying agent is operation intermediary who operates group-buying activities professionally. It is entrusted by the seller, gets profits through charging commissions [2] and affects the seller's group-buying price with commissions. For agent who is channel leader, commission decisions are related to its own income and directly impact on the income of the seller or even the profits of the whole distribution channel. So how to make the commission decisions is important issue that needs to be resolved.

In existing literature, the two-party pricing decision of distribution channel is more common in the supply chain channel coordination study. Moorthy $\mathrm{K}$ [3] pointed out the "double marginalization effect" of suppliers and retailers that the two parties independent pricing will reduce revenue in monopoly market [3]. Rajeev Kohli proved that the two parties cooperate with each other can achieve overall revenue maximization with bargaining game model [4]. In these studies, the pricing mechanism of distribution channel is fixed-price mechanism. However, due to the differences between the group-buying pricing mechanism and fixed price mechanism, online group-buying agent can not directly use the research results for decision-making.

Correspondingly, in field of online group-buying research literatures are mostly focused on relationship of buyers and sellers, while ignoring the important third party in the practical application: agent. Jian Chen et al. [5] [6] regarded group-buying on the web as an auction mechanism, got the methods for sellers determining the online groupbuying price sequence and price qualifications through analyzing online group-buying mechanism and bidder behavior and pointed out the qualifications of this mechanism is more dominant than fixed-price mechanism. Anand et al [7] proved online group-buying mechanism is more dominant than fixed-price mechanism through comparing revenue of each mechanism in uncertain monopolize the market condition. He also proved methods for sellers determining online group-buying price sequence and price qualifications with optimal method using applied economics theory. Although there are differences in the application of principles and methods, the researches have similar conclusions that group-buying mechanism is more dominant than fix-price mechanism in two conditions one is uncertain market, the other one is on-demand production and products with economies of scale. This conclusion highlights why online group-buying mechanism can applicant successfully. However, none of above literatures relate to agent involved situation.

At present, although the network group-buying distribution channels constituted by sellers and agents are very extremely common, there are few literatures studying on this particular mechanism. Based on above, this paper bases on the agents' perspective, analyzes the game relationship between sellers and agents in distribution channels of online group-buying and discusses the following questions related to agent commission:

In online group-buying mechanism, what kind of mission charging method which agents can achieve their own optimal revenues? What kind of influence on online group-buying pricing and gains of both parties that the agents charge different commission. Whether the online group-buying mechanism is still better than the fixed-price 
mechanism? How the agents and sellers cooperate with each other to optimize all parties' revenues.

\section{BASIC SETTINGS}

Online group-buying pricing mechanism is mainly characterized as:

Group-buying price is not a single fixed price but constituted by a series of descending prices, called groupbuying sequence prices, such as a sequence prices constituted by $\mathrm{n}$ group-buying prices (p1,p2,..,pn), andp1>p2> ... >pn;

Each online group-buying purchase quantity has a price corresponding to the sequence price, forming an increasing sequence quantities (q1,q2,..,qn), and $\mathrm{q} 1<\mathrm{q} 2<\ldots<\mathrm{qn}$;

The transaction deals according to the lowest price in the qualifications

This paper sets an online group-buying distribution channel constituted by a seller and a group-buying agent to study on the issues of agent commission. The seller produces some kind of a group-buying product and sells by the agent through online group-buying. The group-buying sequence of price is made by the seller in the distribution channel. The agent gains the commission through two ways. One is unit fixed commission that the agent charges the unit commission whatever the price of the group-buying deals. The other is unit variable commission that the agent charges the commission according to the price of the group-buying deals. Based on the characteristics of online group-buying pricing mechanism referring existing literatures, this paper set following assumptions.

Monopoly market. In the monopoly market, the seller sells some kind of a product. The market has not other enterprise, and there is no alternative;

Uncertain cross demand. This product has two uncertain demands in the market which called low and high demand according to the price elasticity for the convenience of description. Two demands are linear monotonically decreasing function. Two demands are irrelevant and independent. The curves of demands intersect ( figure 1);

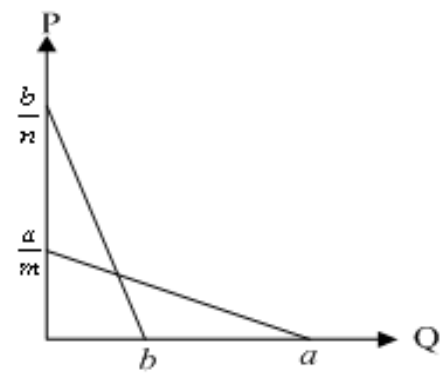

Figure 1. Cross-demand

Product cost. To simplify the analysis, assuming the fixed cost of sellers' production is 0 and unit variable cost is c.

Produce in accordance with the needs. The seller production should have sufficient flexibility, in accordance with actual demands, and the production capacity is sufficient which can meet market demands;
Rational man. Sellers and agents are rational man and expect to maximize profits.

Single-cycle. The sellers and agents game once, and the repeat game is not considered.

Complete information assumptions. Sellers and agents are able to get all information including product demands and costs.

Based on the above assumptions, this paper establishes pricing model parameters as shown in Table 1:

TABLE I. PARAMETERS AGENT COMMISSION DECISION MODEL

\begin{tabular}{|c|c|}
\hline $\begin{array}{c}\text { paramete } \\
\mathbf{r}\end{array}$ & parameter meaning \\
\hline$b$ & Market capacity in low demand, $b>0$ \\
\hline$n$ & Price elasticity of demand in low demand, $n>0$ \\
\hline$a$ & The market capacity in high demand, $a>0$ \\
\hline$m$ & Price elasticity of demand in high demand, $m>0$ \\
\hline$\gamma$ & $\begin{array}{l}\text { probability of low demand, probability of high demand is } \\
\qquad(1-\gamma), \quad \gamma \in(0,1)\end{array}$ \\
\hline$c_{s}, c_{a}$ & $c_{s}$ is variable costs of seller,$c_{a}$ is variable costs of agent. \\
\hline$p_{1}, p_{2}$ & $\begin{array}{l}\text { Seller formulates the group-buying sequence prices, the } \\
p_{1} \text { is the price in low demand, } p_{2} \text { is the price in high } \\
\text { demand, } p_{1}>p_{2}>c\end{array}$ \\
\hline$q_{1}, q_{2}$ & $\begin{array}{l}\text { Seller formulates the qualification of purchase quantity } \\
\text { corresponding to each group-buying price, } q_{i}(i=1,2) \\
\text { represents when the purchase quantity does not exceed } \\
\qquad q_{i} \text {, the selling price } p_{i} \cdot q_{2}=+\infty>q_{1}\end{array}$ \\
\hline$k$ & The unit fixed commission determined by the agent \\
\hline$k_{1}, k_{2}$ & $\begin{array}{l}\text { Unit variable commission determined by the agent, } k_{1} \\
\text { represents the unit commission when group-buying price } \\
\text { is } p_{1}, k_{2} \text { represents the unit commission when group- } \\
\text { buying price is } p_{2}\end{array}$ \\
\hline$Q_{L}, Q_{H}$ & $\begin{array}{l}Q_{L} Q \text { are the demand quantity in low demand and high } \\
\text { demand, } Q_{L}>0, Q_{H}>0\end{array}$ \\
\hline$\pi_{g s}, \pi_{f s}$ & $\begin{array}{l}\text { Expected revenue of seller, } g \text { represents online group- } \\
\text { buying mechanism, } f \text { represents fixed pricing mechanism }\end{array}$ \\
\hline$\pi_{g a}, \pi_{f a}$ & $\begin{array}{l}\text { Expected revenue of agent, } g \text { represents online group- } \\
\text { buying mechanism, } f \text { represents fixed pricing mechanism }\end{array}$ \\
\hline$\pi_{g t}, \pi_{f t}$ & $\begin{array}{l}\text { Total revenue of distribution channel, } g \text { represents } \\
\text { online group-buying mechanism, } f \text { represents fixed } \\
\text { pricing mechanism }\end{array}$ \\
\hline$j$ & $j$ is subscript, $j$ represents cooperation \\
\hline
\end{tabular}

Base on above parameter settings, the market demand function in low demand is $Q_{L}=b-n p$, the market demand function in high demand is $Q_{H}=a-m p$. The probability of two demands are $\gamma$ and $(1-\gamma)$. As the demand curve intersect, $n a / m<b<a$. There are two uncertainty demand including low demand and high demand, so the seller revenue functions including group-buying mechanism and fixed pricing mechanism are as follows:

$$
\begin{aligned}
& \pi_{g s}=\gamma\left(p_{1}-k\right)\left(b-n p_{1}\right)+(1-\gamma)\left(p_{2}-k\right)\left(a-m p_{2}\right) \\
& \pi_{f s}=\gamma(p-k)(b-n p)+(1-\gamma)(p-k)(a-m p)
\end{aligned}
$$

Using optimization method to solve the optimal revenue in two mechanisms, the result shows that the online groupbuying mechanism is dominant in the fixed pricing mechanism. The revenue and revenue comparison of two mechanisms as equation (2) shows: 


$$
\begin{aligned}
& \pi_{f s}\left(p^{*}\right)=\frac{\left(\gamma b+(1-\gamma) a-c_{s}(\gamma n+(1-\gamma) m)\right)^{2}}{4(\gamma n+(1-\gamma) m)} \\
& \text { where } p^{*}=\frac{\gamma b+(1-\gamma) a+c_{s}(\gamma n+(1-\gamma) m)}{2(\gamma n+(1-\gamma) m)} \\
& \pi_{g s}\left(p_{1}^{*}, p_{2}^{*}\right)=\frac{\gamma\left(b-c_{s} n\right)^{2} m+(1-\gamma)\left(a-c_{s} m\right)^{2} n}{4 m n} \\
& \text { where }\left\{\begin{array}{l}
p_{1}^{*}=\frac{b+c_{s} n}{2 n}, \text { if } q_{1} \leq b-n\left(\frac{a+c_{s} m}{2 m}\right) \\
p_{2}^{*}=\frac{a+c_{s} m}{2 m}, \text { otherwise. } \\
\pi_{g s}-\pi_{f s}=\frac{(1-\gamma) \gamma(m b-n a)^{2}}{4 n m(\gamma n+(1-\gamma) m)} \geq 0 \quad \forall \frac{n a}{m}<b<a
\end{array}\right.
\end{aligned}
$$

When distribution channel is constituted by the seller and agents, the seller pays not only unit variable cost of group-buying products but also agent commission. Obviously the commission increases the seller unit variable. The online group-buying mechanism is still dominant in fixed pricing mechanism. If the agent charges unit fixed commission $\mathrm{k}$, the revenues of seller and agent are as formula (3). If the agent charges variable commission, the revenues of seller and agent are as formula (4). The distribution revenue is the sum of both parties' revenues.

$$
\begin{aligned}
& \pi_{g s}=\gamma\left(p_{1}-k-c_{s}\right)\left(b-n p_{1}\right)+(1-\gamma)\left(p_{2}-k-c_{s}\right)\left(a-m p_{2}\right) \\
& \pi_{g a}=\gamma\left(k-c_{a}\right)\left(b-n p_{1}\right)+(1-\gamma)\left(k-c_{a}\right)\left(a-m p_{2}\right) \\
& \pi_{g s}=\gamma\left(p_{1}-k_{1}\right)\left(b-n p_{1}\right)+(1-\gamma)\left(p_{2}-k_{2}\right)\left(a-m p_{2}\right) \\
& \pi_{g a}=\gamma k_{1}\left(b-n p_{1}\right)+(1-\gamma) k_{2}\left(a-m p_{2}\right)
\end{aligned}
$$

Based on the decision making feature of pricing and commission, this paper establish Stackelberg game model to analyze the relationship of two parties. Firstly, define commission reaction function of seller to agent. Secondly, agent chooses optimal method to gain commission and optimal commission referring to sellers' pricing. At last determine group-buying sequence price and qualification.

\section{AGENT COMMISSION IN CASE OF NON-COOPERATIVE}

This section discusses decisions the two parties make in case of non-cooperative that seller and agent determine commission, group-buying price and qualification aiming to maximize revenue themselves. This section discusses two conditions according to the methods of agent charging commission.

\section{A. Unit fixed Commission}

According to the former hypothesis, agent is dominant in the distribution channel that agent can access the information of the sellers' margin profit in the process of game. Agent can get the optimal group-buying sequence price $\left(p_{1}{ }^{*}, p_{2}{ }^{*}\right)$, and determines the optimal unit commission $k^{*}$ according to the sequence price aiming to get optimal revenue of group-buying agent.
According to backward induction method of stackelberg game, when agent charges unit fixed commission, it can get following lemma:

Lemma 1: when agent charges unit fixed commission, the optimal revenues of both parties in the distribution channel are:

1) the optimal revenue of agent and corresponding unit commission

$\pi_{g a}=\frac{\left(\gamma b+(1-\gamma) a-\left(c_{s}+c_{a}\right)(\gamma n+(1-\gamma) m)\right)^{2}}{8(\gamma n+(1-\gamma) m)}$

where $k^{*}=\frac{\gamma b+(1-\gamma) a}{2(\gamma n+(1-\gamma) m)}$

2) the optimal revenue of seller, corresponding price of group-buying and qualification

$$
\begin{aligned}
& \pi_{g s}= \frac{\gamma^{2} m n\left(b-\left(c_{s}+c_{a}\right) n\right)^{2}+(1-\gamma)^{2} m\left(a-\left(c_{s}+c_{a}\right) m\right)^{2} n}{16 m n(\gamma n+(1-\gamma) m)}+ \\
& \frac{2 \gamma(1-\gamma)\left(2 b^{2} m^{2}-b m\left(3 a+\left(c_{s}+c_{a}\right) m\right) n\right)}{16 m n(\gamma n+(1-\gamma) m)} \\
& \frac{2 \gamma(1-\gamma) n^{2}\left(2 a^{2}-a\left(c_{s}+c_{a}\right) m+\left(c_{s}+c_{a}\right)^{2} m^{2}\right)}{16 m n(\gamma n+(1-\gamma) m)} \\
& \text { where }\left\{\begin{array}{l}
p_{1}^{*}=\frac{b((3 \gamma n+2(1-\gamma) m))+n\left(a(1-\gamma)+\left(c_{s}+c_{a}\right)(\gamma n+(1-\gamma) m)\right)}{4 n(\gamma n+(1-\gamma) m)} \\
\text { if } q_{1}<b-n p_{2}^{*}, \\
p_{2}^{*}=\frac{\gamma b m+\left(c_{s}+c_{a}\right) m(\gamma n+(1-\gamma) m)+a(2 \gamma n+3(1-\gamma) m)}{4 m(\gamma n+(1-\gamma) m)}
\end{array}\right.
\end{aligned}
$$

\section{3) revenues following the entire sales channel}

$\pi_{g t}=\frac{\left(\gamma m b^{2}(3 \gamma n+4(1-\gamma) m)+(1-\gamma) n a^{2}(4 \gamma n+3(1-\gamma) m)\right)-2 \gamma(1-\gamma) m n a b}{16 m n(\gamma n+(1-\gamma) m)}$

Proof: Firstly calculate partial derivative of sellers' revenue and sellers' sequence price. Group-buying sequence price $\mathrm{p} 1 *=(\mathrm{b}+\mathrm{csn}+\mathrm{nk}) / 2 n, p_{2}{ }^{*}=\left(a+c_{s} n+m k\right) / 2 m$ can be obtained from seller's revenue function in formula (3) and $\partial \pi_{g s} / \partial p_{1}=0 、 \partial \pi_{s} / \partial p_{2}=0$ that is qualification of first partial derivative of $\left(p_{1}, p_{2}\right)$. Group-buying sequence price is the function of seller reacts to the agent commission determination. Taking $p_{1}{ }^{*}, p_{2}{ }^{*}$ into agent's revenue function in formula (3), it can get the agent's revenue and optimal unit fixed commission $k^{*}$ shown formula (5). Secondly taking $k^{*}$ into seller's revenue function, it can get seller's revenue and optimal group-buying sequence price $\left(p_{1}{ }^{*}, p_{2}{ }^{*}\right)$ shown in formula (6). Finally it is necessary to verify if $\left(p_{1}{ }^{*}, p_{2}{ }^{*}\right)$ and corresponding qualification achieve the requirement of group-buying mechanism. Because of the cross-demand assumption that $m b>n a$ of and $p_{1}{ }^{*}-p_{2}{ }^{*}=(m b$ $n a) / 2 m n>0$, so $p_{1}{ }^{*}>p_{2}{ }^{*}>0$.In this condition, seller can set up group-buying price qualification as $\left(q_{1}=b-p_{2}{ }^{*}, q_{2}=+\infty\right)$ if it wants to prevent price from falling to $p_{2}{ }^{*}$ when low demand apper. So the group-buying sequence price made by 
seller and corresponding qualification achieves the requirement of group-buying mechanism. Proof is completed.

\section{B. Unit Variable Commission}

It is assumed that agent determines commission according to the different demand. The agent sets up two different commissions according to group-buying sequence price. According to backward induction method of stackelberg game, the lemma can be obtained as following:

Lemma 2: When agent determines using unit variable commission, $t$ the optimal revenues of both parties in the distribution channel are:

$$
\begin{aligned}
\pi_{g s}= & \frac{1}{16 n m}\left((1-\gamma)\left(m n a^{2}-2 m n a\left(c_{s}+c_{a}\right)\right)+m\left(\gamma b^{2}-2 \gamma n b c_{s}+\right.\right. \\
& \left.n(\gamma n+(1-\gamma) m)\left(c_{s}^{2}+c_{a}^{2}\right)+2 n c_{a}\left(c_{s}(\gamma n+(1-\gamma) m-\gamma b)\right)\right) \\
\pi_{g a}= & \frac{1}{8 n m}\left((1-\gamma)\left(m n a^{2}-2 m n a\left(c_{s}+c_{a}\right)\right)+m\left(\gamma b^{2}-2 \gamma n b c_{s}+\right.\right. \\
& \left.n(\gamma n+(1-\gamma) m)\left(c_{s}^{2}+c_{a}^{2}\right)+2 n c_{a}\left(c_{s}(\gamma n+(1-\gamma) m-\gamma b)\right)\right) \\
\pi_{g t}= & \frac{3}{16 n m}\left((1-\gamma)\left(m n a^{2}-2 m n a\left(c_{s}+c_{a}\right)\right)+m\left(\gamma b^{2}-2 \gamma n b c_{s}+\right.\right. \\
& \left.n(\gamma n+(1-\gamma) m)\left(c_{s}^{2}+c_{a}^{2}\right)+2 n c_{a}\left(c_{s}(\gamma n+(1-\gamma) m-\gamma b)\right)\right) \\
\text { where } & \begin{array}{l}
p_{1}^{*}=\frac{3 b+n c_{s}+n c_{a}}{4 n}, k_{1}^{*}=\frac{b-n c_{s}+n c_{a}}{2 n}, q_{1} \leq b-\frac{3 a+m c_{s}+m c_{a}}{4 m} ; \\
p_{2}^{*}=\frac{3 a+m c_{s}+m c_{a}}{4 m}, k_{2}^{*}=\frac{a-m c_{s}+m c_{a}}{2 m}, q_{1}>b-\frac{3 a+m c_{s}+m c_{a}}{4 m}
\end{array}
\end{aligned}
$$

Proof: Based on proposition 3-5, agent will charge variable commission when group-buying demand quantity meet the qualification of cross-demand and the seller sets up corresponding sequence price. So the functions of seller reacts agent charging variable commission are $p_{l}=\left(b+n\left(k_{1}+c_{s}\right)\right) / 2 n 、 p_{2}=\left(a+m\left(k_{2}+c_{s}\right)\right) / 2 m$. Taking the functions into formula (8), $k_{l}{ }^{*}=\left(b-n c_{s}+n c_{a}\right) / 2 n 、 k_{2}{ }^{*}=(a-$ $\left.m c_{s}+m c_{a}\right) / 2 m$ can be obtained. Group-buying sequence price $\left(p_{1}{ }^{*}=\left(3 b-n c_{s}+n c_{a}\right) / 4 n, p_{2}{ }^{*}=\left(3 a-m c_{s}+m c_{a}\right) / 4 m\right)$ can be obtained through $k_{1}{ }^{*} 、 k_{2}{ }^{*}$. $p_{1}{ }^{*}$ corresponding qualification of group-buying price is $\left.q_{1}<a-\left(3 a-m c_{s}+m c_{a}\right) / 4 m\right), p_{2}{ }^{*}$ corresponding qualification of group-buying price is $q_{2}=+\infty$, so $p_{1}{ }^{*}>p_{2}{ }^{*} 、 q_{1}<q_{2}$ can be abstained that meet the qualification of group-buying pricing. Taking $p_{1}{ }^{*} 、 p_{2}{ }^{*}$ 、

$k_{1}{ }^{*} 、 k_{2}{ }^{*}$ into revenue functions of both parties shown in formula (8). Proof is completed.

Proposition 1 can be obtained through comparing different commission charging methods based on Lemma 1 and Lemma 2.

Proposition 1: The revenue of unit variable commission agent charges is more than the unit fixed commission When the seller sets up group-buying sequence price $\left(p_{1}, p_{2}\right)$ according to uncertain demand and entrusts group-buying to agent. Sellers' revenue and total revenue of the system will reduce if agent charges unit fixed commission. $D_{s} 、 D_{a} 、 D_{t}$ are on the behalf of the revenue differences between unit variable commission and unit fixed commission of seller, agent, and distribution channel. Conclusions are as follows:
Revenue difference of agent determining difference commission is as formula (9). So the method of unit variable commission is more dominant than unit fixed commission.

$D_{a}=\frac{\gamma(1-\gamma)(b m-n a)^{2}}{8 m n(\gamma n+(1-\gamma) m)}>0$

Revenue difference of seller is as formula (10) in case of agent charging different commission methods. So seller gains more revenue when agent charges unit fixed commission.

$D_{s}=-\frac{3 \gamma(1-\gamma)(b m-n a)^{2}}{16 m n(\gamma n+(1-\gamma) m)}<0$

Total revenue differences of distribution in case of two kinds of commissions charging mode is as formula (11). Unit variable commission reduces the total revenue of group-buying channel.

$$
D_{t}=-\frac{\gamma(1-\gamma)(b m-n a)^{2}}{16 m n(\gamma n+(1-\gamma) m)}<0
$$

Proof: On basis of subgame equilibrium conclusion of lemma1 and lemma 2, revenue difference of each parties in terms of different commission charging method can be obtained

Proposition 1 reveals agent charging commission influences all parties' revenue. Indicating under the terms of assumptions established, agent should determine decision of commission based on the seller's group-buying sequence price. Agent gains more revenue if agent charges unit variable commission according to group-buying sequence price.

\section{Fixed Pricing Mechanism}

Assuming application qualification is that seller sets up a fixed price only and entrusts act on behalf of group-buying. Set up sellers' fixed price p. Under the terms of fixed pricing mechanism, agent can adopt unit fixed commission only. So set up unit fixed commission $\mathrm{k}$. Optimal revenue of each parties in the channel is as lemma 3 through Stackelberg game.

Lemma 3: Under the terms of cross-demand when seller uses fixed price mechanism, optimal solution of each parties revenue, price, and commission is as formula (12): 


$$
\begin{gathered}
\pi_{f s}=\frac{\left(\gamma b+(1-\gamma) a-\left(c_{s}+c_{a}\right)(\gamma n+(1-\gamma) m)\right)^{2}}{16(\gamma n+(1-\gamma) m)} \\
\text { where } p^{*}=\frac{3(\gamma b+(1-\gamma) a)+\left(c_{s}+c_{a}\right)(\gamma n+(1-\gamma) m)}{4(\gamma n+(1-\gamma) m)} \\
\pi_{f a}=\frac{\left(\gamma b+(1-\gamma) a-\left(c_{s}+c_{a}\right)(\gamma n+(1-\gamma) m)\right)^{2}}{8(\gamma n+(1-\gamma) m)} \\
\text { where } k^{*}=\frac{\gamma b+(1-\gamma) a+\left(c_{s}+c_{a}\right)(\gamma n+(1-\gamma) m)}{2(\gamma n+(1-\gamma) m)}
\end{gathered}
$$

Proof: In fixed-price mechanism, seller's revenue function is $\pi_{f s}=\gamma(p-k)(b-n p)+(1-\gamma)(p-k)(a-m p)$, agents' revenue function is $\pi_{f a}=\gamma k(b-n p)+(1-\gamma) k(a-m p)$. The function of sellers' determination of fixed price reacting to agent commission can be obtained through backward induction. Taking response function into agent's revenue function, agent optimal commission $k^{*}$ can be obtained through firstorder condition. So optimal revenue of seller and agent is as formula (12), and total revenue of channel is sum of the both sides' revenue. Proof is completed.

On basis of lemma 1,2 and 3, proposition 2 can be obtained comparing revenues under terms of different mechanism.

Proposition 2: Under terms of cross-demand, no matter what kind of commission charging method, online groupbuying mechanism is more dominant than fixed pricing mechanism.

Proof: Es, Ea, Et respectively represents the revenue difference of seller, agent and distribution channel in terms of two mechanism. (Revenue of online group-buying mechanism minus revenue of fixed pricing mechanism). There are:

On basis of lemma 1 and lemma 3, when agent charges unit fixed commission under terms of two mechanisms, the revenue difference of each parties under terms of two mechanism is as formula (13) .

$D_{s}=D_{t}=\frac{\gamma(1-\gamma)(b m-n a)^{2}}{4 m n(\gamma n+(1-\gamma) m)}>0 ; D_{a}=0$

On basis of lemma 2 and lemma 3, the revenue difference of each parties under terms of two mechanism is as formula (14) when agent charges unit fixed commission under terms of fixed mechanism and charges variable commission under terms of group-buying mechanism.

$D_{s}=\frac{\gamma(1-\gamma)(b m-n a)^{2}}{16 m n(\gamma n+(1-\gamma) m)}>0 ; D_{a}=2 D_{s}>0 \quad ; D_{t}=3 D_{s}>0$

Proposition 2 shows in cross-demand condition, on matter what kind of commission charging method agent determined, the application of online group-buying mechanism can increase revenue of each parties which is unanimous with the conclusion of literature [7] under terms of seller autonomous group-buying. If agent charge unit fixed commission, the commission is actually equivalent to average variable cost of seller implementing group-buying. So seller can occupy the increment of revenue exclusively by online group-buying mechanism, while agent's revenue has no difference under terms of different mechanism. If agent charges unit variable commission, seller and agent share revenue increment caused by group-buying mechanism.

Realistic online group-buying mode proofs agent charge commission on basis of group-buying sequence price can bring more revenue for agent on other hand. Analyzing the contract signed by the agents such as Meituan, Lashou websites and sellers, most agents charge unit fixed commission.

\section{COOPERATION PRICING AND COORDINATION MECHANISMS}

\section{A. Qualification of Cooperation Pricing}

Assuming seller sells through group-buying autonomously, that is seller sells through direct channel. Variable cost of seller is $c=c_{s}+c_{a}$. Comparing online groupbuying price of seller in lemma1, lemma 2 and autonomous group-buying price in formula (2), it can be found that when seller entrusts group-buying to agent, no matter what kind of commission charging method agent determined, online group-buying price determined by seller will be higher than the autonomous group-buying price. It represents that revenue under terms of entrusting groupbuying is failed to reach revenue under terms of autonomous group-buying.

Assuming the revenue difference of channel total revenue under terms entrusting group-buying and of autonomous group-buying is $E$. On basis of lemma 1 and formula (2) in terms of unit fixed commission, revenue difference of total channel is $E=-\frac{(\gamma b+(1-\gamma) a)^{2}}{16(\gamma n+(1-\gamma) m)}<0$. On basis of lemma 2 and formula (2) in terms of unit variable commission, revenue difference of total channel is $E=-\frac{\gamma b^{2} m+(1-\gamma) a^{2} n}{16 m n}<0$.

There is still "double marginalization" issue of total channel revenue which can get from revenue difference in terms of different commission charging method, when online distribution channel constituted by seller and agent. This is caused by in the group-buying channel objects of seller and agent are maximizing revenue which conflict with total channel revenue. To prevent the fall of revenue, most literatures suggest a cooperation mechanism or revenue sharing mechanism to allocate revenue and analyze the influence in terms of cooperation through empirical study. Assume pricing tactic is cooperation. Set cost of centralized decision-making mode $c_{j}$, channel revenue as formula (14) and optimal solution of channel revenue as lemma 4 .

Lemma 4: When seller and agent cooperate with each other, the optimal sequence price and revenue of groupbuying channel are: 


$$
\begin{aligned}
& \pi_{g t}=\frac{1}{4}\left(\frac{\gamma\left(b-n c_{s}-n c_{a}\right)^{2}}{n}+\frac{(1-\gamma)\left(a-m c_{s}-m c_{a}\right)^{2}}{m}\right)-c_{j} \\
& \text { where }\left\{\begin{array}{l}
p_{1}^{*}=\frac{b+n c_{s}+n c_{a}}{2 n}, q_{1} \leq b-n\left(\frac{a+m c_{s}+m c_{a}}{2 m}\right) \\
p_{2}^{*}=\frac{a+m c_{s}+m c_{a}}{2 m}, \text { otherwise }
\end{array}\right.
\end{aligned}
$$

Proof: $p_{1}{ }^{*}=\left(b+n c_{s}+n c_{a}\right) / 2 n 、 p_{2}{ }^{*}=\left(a+m c_{s}+m c_{a}\right) / 2 m$ can be obtained from the first order condition. The group-buying price qualification corresponding to $p_{1}{ }^{*}$ is $q_{1}<b$ $\left.\left(a+m c_{s}+m c_{a}\right) / 2 m\right)$, so $p_{1}{ }^{*}>p_{2}{ }^{*} 、 q_{1}<q_{2}$ satisfy the groupbuying price qualification. Taking $p_{1}{ }^{*} 、 p_{2}{ }^{*}$ into formula (14), each parties' revenue and system's revenue can be obtained as formula (15).

Comparing revenue of cooperative and no cooperative condition on basis of lemma 2 and lemma 4, the proposition 3 can be obtained.

Proposition 3: In the online group-buying channel constituted by seller and agent, if cost of cooperation $c_{j}$ satisfy qualification shown in formula (16), agent and seller cooperate with each other can gain the most total revenue of channel.

$$
\begin{aligned}
c_{j}< & \frac{1}{16 n m}\left((1-\gamma)\left(m n a^{2}-2 m n a\left(c_{s}+c_{a}\right)\right)+m\left(\gamma b^{2}-2 \gamma n b c_{s}+\right.\right. \\
& \left.n(\gamma n+(1-\gamma) m)\left(c_{s}^{2}+c_{a}^{2}\right)+2 n c_{a}\left(c_{s}(\gamma n+(1-\gamma) m-\gamma b)\right)\right)
\end{aligned}
$$

Proof: On basis of lemma2 and lemma 4 solving the total revenue of channel in terms of whether cooperate with each other or not separately, the formula (16) can be obtained through total revenue of cooperative condition minus total revenue of no cooperative revenue.

Proposition 3 shows that, if the addition of total revenue both parties cooperate with each other is greater than the cost $c_{j}$ produced, both parties can allocate the addition of revenue according a allocation mechanism, otherwise they don't need to cooperate with each other.

\section{B. Cooperation Mechanism}

When both parties cooperating with each other and satisfy the qualification of proposition 3, total revenue of channel is increased after seller and agent cooperating with each other that is benefit to both parties. However, what kind of cooperative mechanism both parties choused is the most important prerequisite for cooperation. In supply chain decision, there are many cooperative methods for upstream and downstream enterprises, such as quantity discounts and incentives. For group-buying channel, there are two common methods including method of contract and method of additional revenue allocation referring to literatures [8].

\section{1) Method of contact}

Method of contract is group-buying price and commission is signed in a contract by seller and agent. For example, seller and agent agree with the sequence price of group-buying $\left(p_{1}, p_{2}\right)$ which corresponding commission is $\left(k_{1}, k_{2}\right)$, so $\left(p_{1}, k_{1}\right) 、\left(p_{2}, k_{2}\right)$ is the price tactic determined by both parties when corresponding demand appears. These tactics often have more than one feasible solution, so the set of these tactics is called contract curve.

Proposition 3 shows that the seller's revenue when working with agents must be greater than the revenue in non-cooperative condition, otherwise cooperative premise will not exist. According to the hypothesis that seller and agent are rational men, so either party's will accept less revenue in cooperative condition than non-cooperative condition. Set price tactic in terms of cooperation $\left(p_{l j}, k_{l j}\right)$, $\left(p_{2 j}, k_{2 j}\right)$, optimal price tactic in terms of non-cooperation $\left(p_{1}{ }^{*}, k_{1}{ }^{*}\right) 、\left(p_{2}{ }^{*}, k_{2}{ }^{*}\right)$, price tactic should satisfy formula (17)

$$
\left\{\begin{array}{l}
\Delta \pi_{g s}=\pi_{g s j}\left(p_{1 j}, k_{1 j} ; p_{2 j}, k_{2 j}\right)-\pi_{g s}\left(p_{1}^{*}, k_{1}^{*} ; p_{2}^{*}, k_{2}^{*}\right)>0 \\
\Delta \pi_{g a}=\pi_{g a j}\left(p_{1 j}, k_{1 j} ; p_{2 j}, k_{2 j}\right)-\pi_{g a}\left(p_{1}^{*}, k_{1}^{*} ; p_{2}^{*}, k_{2}^{*}\right)>0
\end{array}\right.
$$

On basis of pricing in terms of cooperation and noncooperation, set a contract pricing set $Z$. $Z$ should be nonempty and satisfy formula (18)

$$
Z=\left\{\begin{array}{l}
\left(\begin{array}{l}
p_{1}, k_{1} \\
p_{2}, k_{2}
\end{array}\right)\left|\begin{array}{l}
\frac{b+n c_{s}+n c_{a}}{2 n}<p_{1}<\frac{3 b+n c_{s}+n c_{a}}{4 n}, k_{1}>\frac{b-n c_{s}+n c_{a}}{2 n} \\
2 m
\end{array}\right| p_{2}<\frac{3 a+m c_{s}+m c_{a}}{4 m}, k_{2}>\frac{a-m c_{s}+m c_{a}}{2 m}
\end{array}\right\}
$$

In the set of contract pricing tactic, any $\left(p_{1}, k_{l}\right) 、\left(p_{2}, k_{2}\right)$ $\in Z$ can make both parties revenue not less than revenue in cooperative condition which increases revenue of groupbuying channel. choosing price tactic in the set should refer both parties' positions, capabilities, utilities and other elements, and using game method to solve these issues such as bargain model.

2) Method of additional revenue allocation

The second method is through a simplified profit-sharing mechanism collaborates additional revenue caused by cooperation between the seller and the agent. Assuming a sharing ratio $\lambda$ determined by seller and agent, seller's ratio is $\lambda$, and agent's ratio is $(1-\lambda)$, revenues of seller and agent are as following:

$\left\{\begin{array}{l}\pi_{s}(\lambda)=\pi_{s}+\lambda\left[\left(\pi_{s j}-\pi_{s}\right)+\left(\pi_{a j}-\pi_{a}\right)\right] \\ \pi_{a}(\lambda)=\pi_{a}+(1-\lambda)\left[\left(\pi_{s j}-\pi_{s}\right)+\left(\pi_{a j}-\pi_{a}\right)\right]\end{array}\right.$

$\lambda$ quantifies the coordination ability of seller. When $\lambda=1$, it indicates seller has absolutely advantage in cooperation and occupies all incremental cooperative revenue, otherwise agent occupies all incremental cooperative revenue. $\lambda$ can be determined referring to bargaining power between two parties in online group-buying channel.

These results indicate that: in the online group-buying channel constituted by seller and agent, if agent and seller cooperate, both parties' and system's revenue may be increased. However, in realistic applications it is difficult to achieve cooperative price of seller and agent because of the pricing cost is too high which offsets revenue increment. In 
the supply chain, the upstream and downstream enterprises adopt cooperative price expecting to establish long-term cooperative partnership. However in the online groupbuying distribution channel, it is difficult for two parties to recognize each cost before cooperative pricing because of short-term cooperation. Meanwhile short-term cooperation makes both parties' hard to trust each other which is needed in cooperative price and establish implementing organization to make unified cooperation price decision.

\section{CONCLUSION}

Online group-buying researches mainly concentrate on game relationship of seller and buyer. However the realistic online distribution channel is constituted by seller and agent. This paper constructs online group-buying channel with seller and agent to analyze price coordination。Firstly, in terms of non-cooperation pricing affects seller, s groupbuying price through charging on basis of both parties game relation. When agent charges commission using groupbuying sequence price, agent can gain more revenue. In this channel whatever kind of commission agent chooses "double marginalization effect" will exist. To solve this issue, this paper discusses the cooperation qualification that cooperation cost is less than the channels total revenue increment. At last, this paper discusses cooperation forms and revenue of both parties.

Further research of online group-buying includes: coordination mechanism of online group-buying channel in mixing mechanism, namely seller's distribution channels include direct channel and online group-buying channel. Extend study range from one single seller cooperates with one single agent to one seller cooperates with multiple agents or multiple sellers cooperate with one agent. In the terms of asymmetric information, discuss seller and agent with principal-agent theory.

\section{ACKNOWLEDGMENT}

This research was supported by MOE (Ministry of Education in China) Project of Humanities and Social Sciences Youth Fund (Project No. 10YJC630190).

\section{REFERENCE}

[1] Dake Qian. Online group-buying [J].Commercial Times,2006.2:pp 67 68

[2] Dake Qian. The forms of online group-buying analysis. [J]Moderrnization.2006.1:pp 36 37

[3] Moorthy K. Managing channel profits: Comment[J]. Marketing Science, 1987,6(4): pp 375-379

[4] Rajeev Kohli and Heungsoo Park. A Cooperative Game Theory Model of Quantity Discounts. Management Science, Vol. 35, No. 6 (Jun., 1989), pp. 693-707

[5] Qian Chen, Xilong Chen, Xiping Song, Jian Chen, Comparison of group-buying auction and fixed-pricing mechanism [J]. Jornal of Management Science in Chan. 2003, 6(5):pp 34-39

[6] Jian Chen, Robert J. Kauffman, Yunhui Liu and Xiping Song. Segmenting uncertain demand in group-buying auctions[J]. Electronic Commerce Research and Applications. 2010.9(2): pp.126-147

[7] Krishnan S. Anand and Ravi Aron. Group Buying on the Web: A Comparison of Price-Discovery Mechanisms [J]. Management Science. 2003.49(11), pp. 1546-1562

[8] Deyi Mou, Fengsheng Tu, Qiushuang Chen. Co-op pricing decision model for manufactureing- retailing supply chain $[\mathrm{J}]$. Acta Scientiarum Natualium Universitatis Nankaiensis(Natual Science Edition).2004.37 (3): pp 55-60 